\title{
Spatial distribution of bivalves in relation to environmental conditions (middle Danube catchment, Hungary)
}

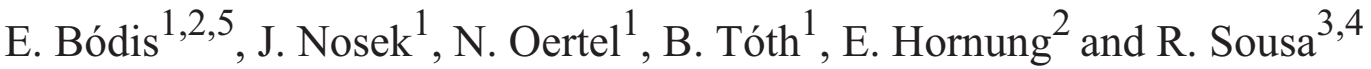 \\ ${ }^{1}$ Hungarian Danube Research Station of the Hungarian Academy of Sciences, Jávorka S. u. 14, H-2131, Göd, \\ Hungary \\ ${ }^{2}$ Szent Istvan University, Faculty of Veterinary Science, Department of Ecology, Institute for Biology, POB 2, \\ H-1400, Budapest, Hungary \\ ${ }^{3}$ CBMA - Centre of Molecular and Environmental Biology, Department of Biology, University of Minho, Campus de \\ Gualtar, 4710-057 Braga, Portugal \\ ${ }^{4}$ CIMAR-LA/CIIMAR - Centre of Marine and Environmental Research, Rua dos Bragas 289, 4050-123 Porto, \\ Portugal \\ ${ }^{5}$ Corresponding author.E-mail: bodiserk@gmail.com
}

Keywords: Bivalves, Invasive species, River Danube, River Ipoly, Spatial pattern.

\begin{abstract}
The spatial distribution of bivalves in relation to environmental conditions was studied along a second- and third order stream - medium-sized river (River Ipoly) - large river (River Danube) continuum in the Hungarian Danube River system. Quantitative samples were collected four times in 2007 and a total of 1662 specimens, belonging to 22 bivalve species were identified. Among these species, two are endangered (Pseudanodonta complanata, Unio crassus) and five are invasive (Dreissena polymorpha, D. rostriformis bugensis, Corbicula fluminea, C. fluminalis, Anodonta woodiana) in Hungary. The higher density presented by Pisidium subtruncatum, $P$. supinum, $P$. henslowanum and $C$. fluminea suggests that these species may have a key role in this ecosystem. Three different faunal groups were distinguished but no significant temporal change was detected. The lowest density and diversity with two species (P. casertanum and P. personatum) occurred in streams. The highest density and diversity was found in the River Ipoly, in the side arms of the Danube and in the main arm of the Danube with sand and silt substrate, being dominated by $P$. subtruncatum and $P$. henslowanum. Moderate density and species richness were observed in the main arm of the Danube with pebble and stone substrate, being dominated by $C$. fluminea and $S$. rivicola. Ten environmental variables were found to have significant influence on the distribution of bivalves, the strongest explanatory factors being substrate types, current velocity and sedimentological characteristics.
\end{abstract}

Abbreviations: PCA - Principal Components Analysis, CCA - Canonical Correspondence Analysis, TBOM - total benthic organic matter, $\mathrm{CBOM}$ - benthic organic matter content in coarse fraction of sediment, FBOM - benthic organic matter content in fine fraction of sediment, VBOM - benthic organic matter content in very fine fraction of sediment, UBOM - benthic organic matter content in ultra fine fraction of sediment

Nomenclature: Checklist of the European Continental Mollusca (Falkner et al. 2001) and the catalogue of Fehér and Gubányi (2001) reflecting the Hungarian situation.

\section{Introduction}

One of the most important tasks of freshwater ecologists is to understand the structure and function of stream ecosystems which includes the distributional pattern of species. Benthic communities are adapted to utilize the structural and resource features of particular habitats. The geomorphic characteristics influence the benthic community structure at a local scale (Huryn and Wallace 1987), while the longitudinal features alter the benthic community structure at a landscape scale (Vannote et al. 1980, Minshall et al. 1985). The interplay of longitudinal and local physical characteristics produces distinct patterns in the structure of benthic communities along a river continuum.

Basic ecological information about freshwater bivalves can be particularly important since these species have signifi- cant traits that make them fundamental in aquatic ecosystems. As filter-feeding organisms, they have an essential role in the flux of matter and energy and they are a connecting link between the primary production and the detritus chain (Strayer et al. 2004). They contribute to the natural purification of water by filtration (both in suspension and in the sediment layer). They have a significant function in the nutrient dynamics of waters and in the aquatic food web as important food sources for fishes, birds and insects (Vaughn and Hakenkamp 2001). However, in spite of their central role in aquatic ecosystems, the distribution patterns of freshwater bivalves, variation in abundance and habitat requirements, especially for the small-sized but abundant species from the Sphaeriidae family, are hardly investigated in riverine ecosystems. The longitudinal pattern of a complete fauna of freshwater bivalves was first discussed by Mouthon (1981). 
He discerned special malacological communities (so-called „malacotypes”) from the hypocrenon to the hypopotamon according to the principle of zonation. Based on quantitative data and an extended survey, Mouthon (1999) later confirmed the general existence of the longitudinal pattern of malacofauna. However, there are only few data about the distributional pattern of total bivalve fauna in the Hungarian Danube River system (Bódis et al. 2008a,b, Richnovszky 1967, Varga and Csányi 1996, Varga et al. 1998-99) and there is an almost complete lack of quantitative surveys, except two from a smaller area (Bódis 2007a, Szekeres et al. 2009). The investigation of bivalves in the Hungarian Danube section is particularly important and up to date in terms of invasion biology as well. The study of several invasive bivalve species is on the agenda, because they are expanding their distribution from both ends of the unified European water system (Bij de Vaate et al. 2002). These invasive bivalves could have a great impact on native biota by changing the population dynamics, the nutrient cycles and energy flow in communities (Haas et al. 2002, Vaughn and Spooner 2006, Sousa et al. 2009).

The first objective of this study was to characterize the bivalve fauna in the catchment of River Danube along a second- and third order stream - medium-sized river (River Ipoly) - large river (River Danube) continuum as a reference for further malacological works, and in particular, to survey the occurrence and distribution of endangered and expanding invasive species. The second objective was to obtain data about the spatial and temporal variation in the abundance of the species and to reveal possible key species present in this ecosystem. The third objective was to study the distributional pattern of bivalves in relation to environmental factors at local and landscape scales.

\section{Material and methods}

\section{Study area}

We studied the bivalves of four running waters (two streams, a medium-sized river and a large river) located in the water system of the Danube, Hungary. The Danube is the longest river (2857 km in length) of Central-Europe. It receives all the running waters of Hungary in a length of 417 $\mathrm{km}$ and has a catchment area of $39000 \mathrm{~km}^{2}$ in this country. Its average water discharge is approximately $2200 \mathrm{~m}^{3} \mathrm{~s}^{-1}$. The riverbed slope is high in the upper section from Bratislava to Szap (30-35 $\mathrm{cm} \mathrm{km}^{-1}$ ), decreases between Szap and the mouth of River Ipoly $\left(8-12 \mathrm{~cm} \mathrm{~km}^{-1}\right)$, decreases again from the mouth of River Ipoly to Paks $\left(7-10 \mathrm{~cm} \mathrm{~km}^{-1}\right)$ and it is the lowest downstream to Paks $\left(5 \mathrm{~cm} \mathrm{~km}^{-1}\right)$ (Töry 1952). The current velocity, according to the slope, decreases along the river, and therefore the proportion of the coarse fraction of the sediments decreases.

The medium-sized River Ipoly is the biggest tributary on the left side of the Hungarian Danube section. Formerly its length had been $257 \mathrm{~km}$, but it was shortened to $215 \mathrm{~km}$ due to the river regulation and the catchment area is $5108 \mathrm{~km}^{2}$ (1430 $\mathrm{km}^{2}$ in Hungary). Water discharge ranges from $3 \mathrm{~m}^{3}$ $\mathrm{s}^{-1}$ to $360 \mathrm{~m}^{3} \mathrm{~s}^{-1}$ with an annual average of $21 \mathrm{~m}^{3} \mathrm{~s}^{-1}$. The floodplain of River Ipoly contains a large quantity of pools, its valley is wide and its slope is low. Small streams with high slope run into the valley of River Ipoly, which has a drainage system in the Mountain Börzsöny. In accordance with the small expanse and variable geographic structure of Mountain Börzsöny, its streams (Hosszúvölgyi and Börzsönyi) are relatively short $(5-25 \mathrm{~km}$ long) and characterized by low water discharge with high fluctuation ranging from 1-2 $\mathrm{m}^{3}$ $\mathrm{s}^{-1}$ to $40 \mathrm{~m}^{3} \mathrm{~s}^{-1}$.

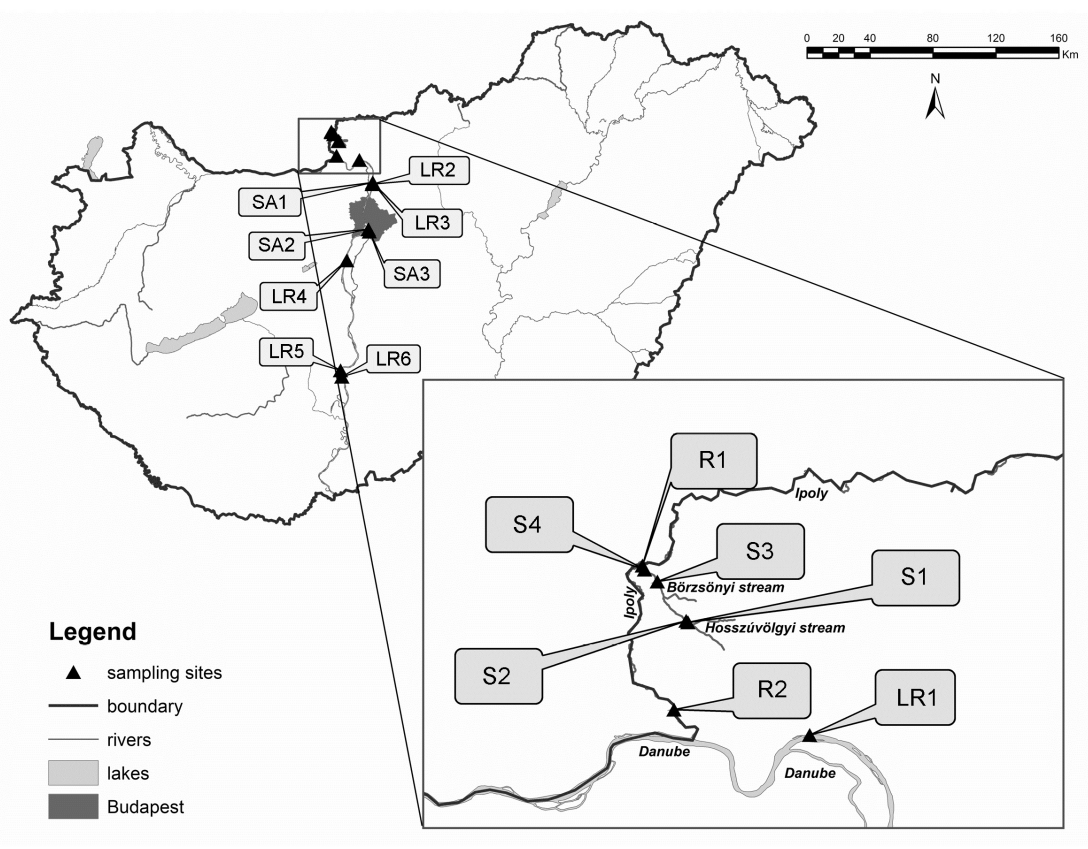

Figu re 1. Map of the sampling sites. 


\section{Sampling and laboratory analysis}

Sampling sites (15 in total) were located along a continuum from a second order stream to the River Danube: second order Hosszúvölgyi-stream (two sites: S1 and S2); third order Börzsönyi-stream (two sites: S3 and S4); fourth order River Ipoly (two sites: at Vámosmikola (R1) and at Ipolydamásd (R2)); ninth order River Danube: main arm (six sites: at Kismaros (LR1), at Göd (LR2, LR3), at Ercsi (LR4) and at Paks (LR5 and LR6)); side arms (three sites: at Göd (SA1) and in Ráckevei-(Soroksári)-Danube (SA2 and SA3)) (Figure 1).

Quantitative samples of bottom sediment were collected four times (April, June, August and October) in 2007. Sampling was carried out by low water level of the Danube (180$220 \mathrm{~cm}$ measured at Budapest) to ensure sampling at the same place in every occasion. At each sampling site and occasion, four replicates with an area of $0.5 \mathrm{~m}^{2}$ were taken. We used a hand net with an edge of $25 \mathrm{~cm}$ length and mesh size of $500 \mu \mathrm{m}$. Samples were fixed in-situ in $4 \%$ formaldehyde solution. In the laboratory, animals were preserved after separation in $70 \%$ ethanol. Only living individuals were identified. Rare and protected bivalve species of Hungary were registered after the work of Fehér et al. (2004).

Physicochemical variables (temperature, velocity, turbidity, conductivity, redox potential, dissolved oxygen, and $\mathrm{pH})$ were recorded in situ. Temperature, conductivity, redox potential and $\mathrm{pH}$ were measured with a WTW multiline portable meter (WTW, Weilheim, Germany); turbidity was measured with a Lovibond PC Checkit portable meter (Tintometer $\mathrm{GmbH}$, Dortmund, Germany). Water velocity was measured by timing a neutrally buoyant object along $2 \mathrm{~m}$ of reach (Gelwick 1990). Dissolved oxygen was measured by Winkler's method (Felföldy 1987).

To determine the fractions of sediment and organic matter content, bed sediment samples were collected by a core sampler of $4 \mathrm{~cm}$ diameter from the upper $5 \mathrm{~cm}$ layer. Samples of $63 \mathrm{~cm}^{3}$ were separated by a series of sieves to four fractions (Coarse, Fine, Very fine and Ultra fine) and the mass and organic matter content of the fractions (CBOM, FBOM, VBOM and UBOM) were measured (Martinez et al. 1998).

Substrate types (stone, pebble, sand, silt, detritus) and vegetation (riparian vegetation, macrophytes and roots) were assessed at each site, which indicate the bottom texture. We classified substratum particles based on their maximum dimensions, using the modified version of the method of Grossman et al. (1998): stone $(6-30 \mathrm{~cm})$, pebble $(0.2-6 \mathrm{~cm})$, sand $(0.005-0.2 \mathrm{~cm})$, and silt $(<0.005 \mathrm{~cm})$.

Altitude (above see level) was recorded in situ. Distance from the estuary of River Danube as well the dry channel width was determined based on maps and aerial photos.

\section{Data analysis}

Environmental data were analyzed by standardized Principal Components Analysis (PCA) using the PAST program package (Hammer et al. 2001).
Variation in freshwater bivalve assemblages associated with different sites was assessed using the PRIMER package (Clarke and Warwick 2001). Univariate measures included density, number of species, Shannon diversity and Pielou's evenness indices. Similarity matrix between sites was calculated using the Bray-Curtis coefficient and then analyzed using CLUSTER with average-linkage clustering algorithm based on the fourth-root-transformed density data. A twoway crossed ANOSIM2 (Clarke and Green 1988) test was used for searching differences between sites and dates. This non-parametric test compares ranked similarities between and within groups selected a priori. The SIMilarity PERcentages procedure (SIMPER) was used to assess the species contributing most to similarities within assemblages defined by CLUSTER analysis.

To relate the bivalve species composition to environmental variables, Canonical Correspondence Analysis (CCA) was performed using the computer program CaNOCO, version 4.5 (Ter Braak and Smilauer 2002). The length of the ordination gradient was tested by DCA analysis. The gradient length of the first DCA axis was 4.804 suggesting that the use of CCA is the most suitable to our dataset. The most significant environmental variables were selected using the stepwise "forward" selection procedure. An unrestricted random Monte Carlo permutation test was used to determine the significant abiotic effects and to verify the significance of the model.

\section{Results}

\section{Environmental analysis}

The means and standard deviations of the environmental variables are presented in Appendix 1. The water temperature increased from streams to large river and the average water temperature ranged between $13.6^{\circ} \mathrm{C}$ (stream, S4) and $22.8^{\circ} \mathrm{C}$ (Danube, LR6). The average turbidity values varied between $13.7 \mathrm{fnu}(\mathrm{R} 2)$ and $61.0 \mathrm{fnu}$ (LR1) (fnu=Formazin Nephelometric Unit). The conductivity was the highest in the third order stream and in the medium-sized River Ipoly and its average values ranged between $355.8 \mu \mathrm{S} \mathrm{cm}^{-1}$ (S1) and $632.3 \mu \mathrm{S} \mathrm{cm}^{-1}$ (S4). The average redox-potential values varied between $155.5 \mathrm{mV}$ (LR3) and $266 \mathrm{mV}$ (SA2). The average dissolved oxygen values varied between $6.7 \mathrm{mg} \mathrm{l}^{-1}$ (S1, $\mathrm{S} 3, \mathrm{SA} 2)$ and $8.8 \mathrm{mg}^{-1}$ (R2). The average $\mathrm{pH}$ was the lowest in streams and in a side arm of the Danube (Ráckevei-(Soroksári)-Danube) and its values ranged between 8.1 (S3, SA2, SA3) and 8.9 (LR1, LR2, LR3).

The total organic matter content of sediment was higher in streams, in the River Ipoly and in sites of the Danube characterized with ultra fine sediment fraction and its average values ranged from $213.4 \mathrm{~g} \mathrm{~m}^{-2}$ (LR2) to $2881.1 \mathrm{~g} \mathrm{~m}^{-2}$ (LR1). The ratio of sediment fractions changes from upstream to downstream. The coarse fraction of sediment was more abundant in streams, in a side arm of the Danube (Ráckevei(Soroksári)-Danube) and in two sites of the Danube with a substrate type of pebble and stone (LR2 and LR4). 
Table 1. Density, number of species, Pielou's evenness and Shannon diversity of sites in different dates.

\begin{tabular}{|c|c|c|c|c|c|c|c|c|c|c|c|c|c|c|c|}
\hline \multirow{2}{*}{$\begin{array}{c}\text { WATER TYPES } \\
\text { SITES }\end{array}$} & \multicolumn{2}{|c|}{$2^{\text {nd }}$ order stream } & \multicolumn{2}{|c|}{$3^{\text {rd }}$ order stream } & \multicolumn{2}{|c|}{ River Ipoly } & \multicolumn{6}{|c|}{ Main-arm of River Danube } & \multicolumn{3}{|c|}{ Side-arms of River Danube } \\
\hline & s1 & S2 & S3 & $\$ 4$ & R1 & $\mathrm{R} 2$ & LR1 & LR2 & LR3 & LR4 & LR5 & LR6 & SA1 & SA2 & SA3 \\
\hline DATE & & & & & & & & April & & & & & & & \\
\hline Density (ind $\mathrm{m}^{-2}$ ) & 1.5 & 0.0 & 2.5 & 45.5 & 73.0 & 241.5 & 6.0 & 10.5 & 61.5 & 2.0 & 20.0 & 32.5 & 202.0 & 82.5 & 59.5 \\
\hline Number of species & 1 & 0 & 1 & 2 & 4 & 13 & 3 & 4 & 5 & 1 & 4 & 7 & 14 & 11 & 12 \\
\hline Evenness & 0.00 & 0.00 & 0.00 & 0.09 & 0.87 & 0.71 & 0.79 & 0.78 & 0.51 & 0,00 & 0.62 & 0.58 & 0.67 & 0.70 & 0.64 \\
\hline Diversity & 0.00 & 0.00 & 0.00 & 0.06 & 1.21 & 1.83 & 0.87 & 1.08 & 0.82 & 0.00 & 0.86 & 1.12 & 1.78 & 1.69 & 1.60 \\
\hline DATE & & & & & & & & June & & & & & & & \\
\hline Density (ind m ${ }^{-2}$ ) & 0.5 & 1.0 & 0.0 & 30.0 & 162.5 & 125.5 & 135.0 & 13.5 & 230.5 & 22.5 & 53.0 & 139.0 & 64.0 & 209.0 & 86.0 \\
\hline Number of species & 1 & 1 & 0 & 1 & 9 & 12 & 10 & 3 & 7 & 7 & 4 & 12 & 9 & 13 & 9 \\
\hline Evenness & 0.00 & 0.00 & 0.00 & 0.00 & 0.69 & 0.79 & 0.75 & 0.85 & 0.54 & 0.71 & 0.26 & 0.75 & 0.72 & 0.29 & 0.52 \\
\hline Diversity & 0.00 & 0.00 & 0.00 & 0.00 & 1.51 & 1.96 & 1.73 & 0.94 & 1.04 & 1.37 & 0.36 & 1.87 & 1.57 & 0.75 & 1.14 \\
\hline DATE & & & & & & & & August & & & & & & & \\
\hline Density (ind $\mathrm{m}^{-2}$ ) & 0.5 & 0.5 & 0.0 & 0.0 & 15.0 & 34.0 & 36.0 & 38.0 & 308.5 & 4.0 & 15.0 & 45.5 & 9.0 & 23.0 & 77.0 \\
\hline Number of species & 1 & 1 & 0 & 0 & 5 & 12 & 10 & 4 & 8 & 1 & 8 & 11 & 5 & 6 & 10 \\
\hline Evenness & 0.00 & 0.00 & 0.00 & 0.00 & 0.69 & 0.80 & 0.72 & 0.19 & 0.60 & 0.00 & 0.76 & 0.75 & 0.80 & 0.53 & 0.63 \\
\hline Diversity & 0.00 & 0.00 & 0.00 & 0.00 & 1.10 & 2.00 & 1.66 & 0.26 & 1.25 & 0.00 & 1.58 & 1.80 & 1.29 & 0.95 & 1.45 \\
\hline DATE & & & & & & & & October & & & & & & & \\
\hline Density (ind $\mathrm{m}^{-2}$ ) & 0.0 & 0.0 & 0.0 & 0.0 & 24.0 & 9.0 & 438.5 & 9.0 & 310.5 & 6.0 & 4.5 & 62.5 & 8.0 & 92.0 & 105.0 \\
\hline Number of species & 0 & 0 & 0 & 0 & 5 & 7 & 10 & 2 & 9 & 1 & 4 & 8 & 7 & 11 & 14 \\
\hline Evenness & 0.00 & 0.00 & 0.00 & 0.00 & 0.77 & 0.91 & 0.83 & 0.31 & 0.60 & 0.00 & 0.83 & 0.70 & 0.78 & 0.38 & 0.56 \\
\hline Diversity & 0.00 & 0.00 & 0.00 & 0.00 & 1.25 & 1.77 & 1.91 & 0.21 & 1.31 & 0.00 & 1.15 & 1.45 & 1.53 & 0.92 & 1.47 \\
\hline
\end{tabular}

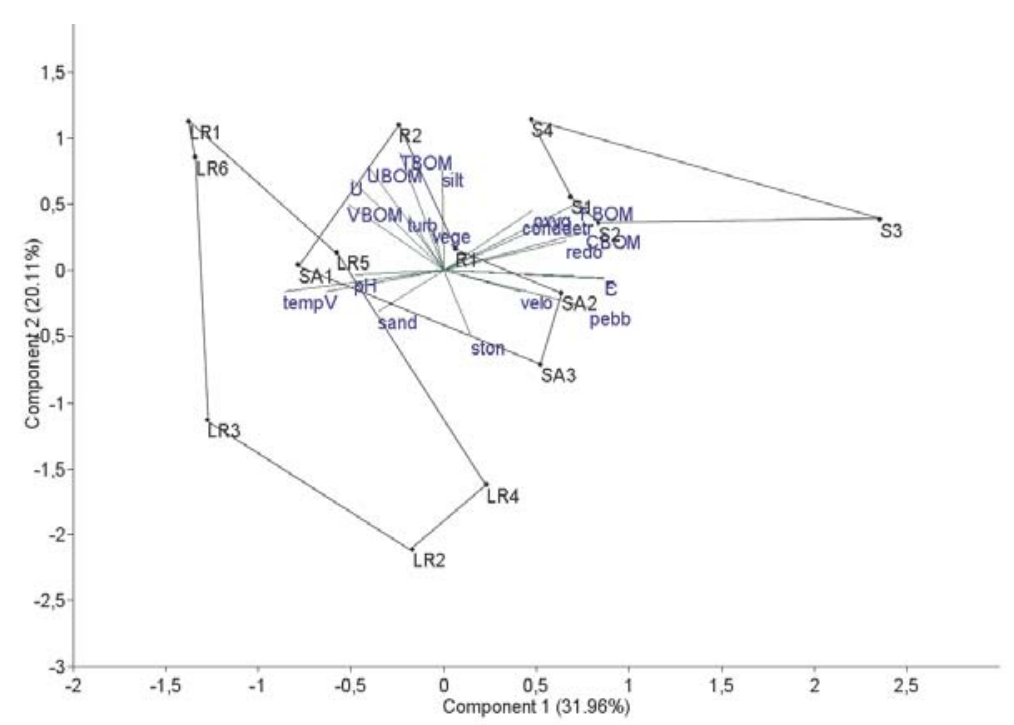

Figure 2. Standardized Principal Component Analysis (PCA) of sampling sites according to the environmental variables along the first two ordination axes. The percentage of variability explained by axes is given. For codes of environmental variables: C-coarse fraction of sediment, F-fine fraction of sediment, V-very fine fraction of sediment, U-ultra fine fraction of sediment, TBOM-total benthic organic matter, CBOM-organic matter content of coarse fraction, FBOM- organic matter content of fine fraction, VBOMorganic matter content of very fine fraction, UBOM- organic matter content of ultra fine fraction, detr-detritus, vege- vegetation, pebb-pebble, ston-stone, velo-velocity, temp-temperature, cond-conductivity, turb-turbidity, redo-redox potential, oxyg-oxygen content of water.

The PCA of environmental factors revealed differences among sites principally based on the sedimenthological characteristics (bed sediment fracions), organic matter content of sediment and substrate types (Figure 2). The first axis explained $31.96 \%$ of variance, it was positively correlated with coarse and fine fraction of sediment, and was negatively correlated with very fine and ultra fine fraction of sediment. From the projection against the first axis of variability, sampling sites were distributed along a sedimentological gradient with the sites characterized with coarser sediments (streams, side arm of the Danube, sites of the main arm of the Danube with pebble and stone) on the positive side and sites with finer sediments (River Ipoly and main arm of the Danube with sand and silt) on the negative side. The second axis explained $20.11 \%$ of variance, it was positively correlated with the total organic matter content of sediment and substrate type of silt, and was negatively correlated with substrate type of stone, pebble and sand. From the projection against the second axis of variability, sites were ordinated along the organic matter content of sediment and substrate types with the 
Table 2. Average similarities for the bivalve groups defined by CLUSTER analysis. Only species which altogether contribute with more than $90 \%$ of total similarity were included.

\begin{tabular}{rccc}
\hline & Group1 & Group2 & Group3 \\
\hline Pisidium casertanum & 100.00 & - & - \\
Pisidium subtruncatum & - & 36.17 & - \\
Pisidium supinum & - & 67.72 & 92.97 \\
Pisidium henslowanum & - & 53.83 & - \\
Corbicula fluminea & - & 75.45 & 79.62 \\
Pisidium amnicum & - & 81.03 & - \\
Sphaerium solidum & - & 86.54 & - \\
Sphaerium corneum & - & 89.18 & - \\
Pisidium moitessierianum & - & 91.10 & - \\
Sphaerium rivicola & - & - & 89.32 \\
\hline
\end{tabular}

sites characterized with silt and vegetation on the positive side (streams, River Ipoly and sites of the main arm of the Danube with silt) and sites with stone, pebble and sand on the negative side (side arm of the Danube, sites of the main arm of the Danube with sand, pebble and stone).

\section{Biological analysis}

In total, 1662 specimens belonging to 22 bivalve species and 1 variety were identified (Appendix 2). Based on the annual cumulative species list, the five most widespread species with their frequency of occurrence were Pisidium casertanum (80.0\%), P. henslowanum and P. supinum (73.3\%), Corbicula fluminea $(66.7 \%)$ and $P$. subtruncatum $(60.0 \%)$. On the basis of relative abundances (number of individuals of the given species / total number of individuals) the five most abundant freshwater bivalves were P. subtruncatum (22.6\%), P. supinum (16.3\%), C. fluminea (14.1\%), P. henslowanum (9.4\%) and Sphaerium solidum (7.9\%).

The density, number of species, Shannon diversity and Pielou's evenness per site had a significant spatial and temporal variation (Table 1 ). The minimum values of density $\left(0.0\right.$ ind $\left.\mathrm{m}^{-2}\right)$ and number of species $(0$ species $)$ were detected in streams, while the lowest values of Shannon diversity index (0) and Pielou's evenness (0) were also found in streams and at site Ercsi (LR4). The stream sites were characterized by changing water discharge ( $\mathrm{S} 4$ was dried out in August), lower water temperature and $\mathrm{pH}$, and coarser sedi-
Table 3. Summary of CCA eigenvalues and cumulative percentage of variance explained on the first four axes.

\begin{tabular}{|c|c|c|c|c|}
\hline & Axis1 & Axis2 & Axis3 & Axis4 \\
\hline Eigenvalues & 0.514 & 0.420 & 0.345 & 0.266 \\
\hline Species-environmental correlation & 0.921 & 0.841 & 0.774 & 0.764 \\
\hline $\begin{array}{c}\text { Cumulative precentage variance } \\
\text { of species data } \\
\text { of species-environment } \\
\text { relationship }\end{array}$ & 11.7 & 21.3 & 29.2 & 35.3 \\
\hline relationship & 23.6 & 42.8 & 58.6 & 70.8 \\
\hline
\end{tabular}

ments compared to other sites. Site Ercsi, situated in the main arm of the River Danube, had a bottom texture of pebbles and stones.

The maximum value of density (438.5 ind. $\mathrm{m}^{-2}$ ) was registered at Kismaros (LR1) in October with the highest annual average percentage of ultra fine sediment and total organic matter content. The maximum value of number of species (14 species) was found in the side arms of the Danube (SA1 in April and SA3 in October). The highest values of diversity and evenness indices were registered in the River Ipoly (R2 in August and in October, respectively). These sites were abundant in vegetation and their current velocity was low.

The ANOSIM2 test based on density similarity revealed a significant difference among sampling sites $(R=0.52$; $\mathrm{P}<0.001)$, but not among months of the year $(\mathrm{R}=0.045$; $\mathrm{p}=0.18)$.

The CLUSTER analysis (Figure 3) reveals three distinct faunal groups and the species responsible for this spatial grouping are given in Table 2.

The sites represented in group $1(\mathrm{~S} 1, \mathrm{~S} 2, \mathrm{~S} 3$ and $\mathrm{S} 4)$ belong to streams with lower water temperature and $\mathrm{pH}$, and higher total organic matter content and coarse fraction of sediment. The density and species richness were very low (mean density, Shannon diversity and Pielou's evenness of 5.1 ind. $\mathrm{m}^{-2}, 0.004$ and 0.006 respectively), and only 2 species were present. The group was characterized by $P$. casertanum. $P$. personatum was found only at the second site of the third order Börzsönyi-stream (S4) close to the conjunction of the Börzsönyi-stream and the River Ipoly.

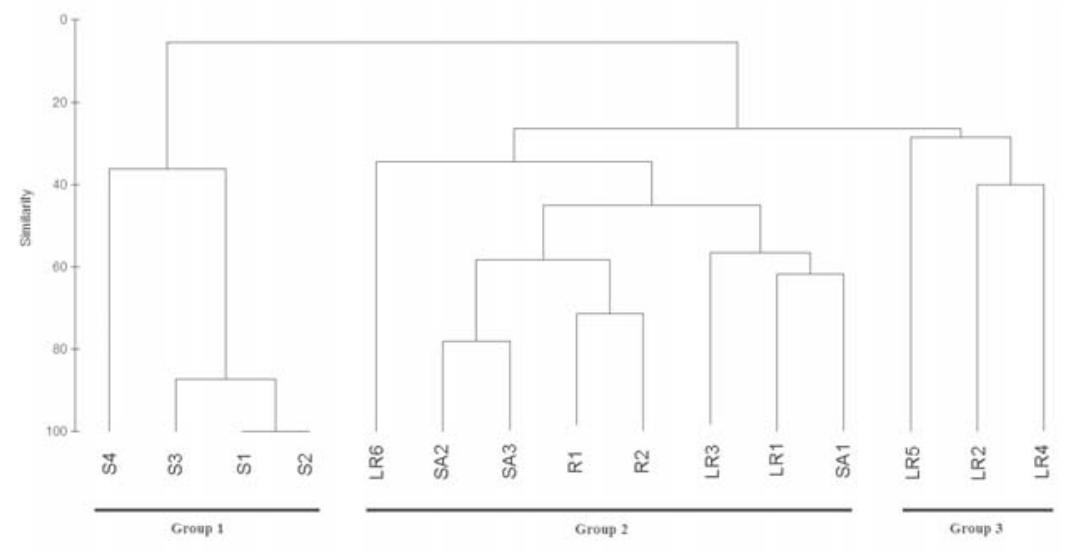

Figu re 3. Hierarchical classification of sampling sites based on bivalve composition (Bray-Curtis coefficient, average-linkage clustering algorithm). 
Table 4. The 10 significant environmental variables defined by Monte Carlo permutation test (999 permutations) in a forward selection procedure.

\begin{tabular}{|c|c|c|c|c|}
\hline & Axis1 & Axis2 & Axis3 & Axis4 \\
\hline Eigenvalues & 0.514 & 0.420 & 0.345 & 0.266 \\
\hline $\begin{array}{l}\text { Species-environmental correlation } \\
\text { Cumulative precentage variance }\end{array}$ & 0.921 & 0.841 & 0.774 & 0.764 \\
\hline $\begin{array}{l}\text { of species data } \\
\text { of species-environment }\end{array}$ & 11.7 & 21.3 & 29.2 & 35.3 \\
\hline relationship & 23.6 & 42.8 & 58.6 & 70.8 \\
\hline
\end{tabular}

Group 2 (LR6, SA2, SA3, R1, R2, LR3, LR1 and SA1) was located at sites of the River Ipoly, in side arms of the Danube and in the main arm of the Danube with bottom texture of silt and sand. This was the most diverse group and the density and diversity indices were high (mean density, Shannon diversity and Pielou's evenness of 109.6 ind. $\mathrm{m}^{-2}, 1.425$ and 0.674 , respectively). A total of 14 species were found and this group was dominated by $P$. subtruncatum, $P$. henslowanum and P. supinum. C. fluminea, P. amnicum, $S$. solidum, $S$. corneum and $P$. moitessierianum also found appropriate habitat conditions here. C. fluminalis (morph-2 under revision, Bódis et al. 2011) occurred only at site Paks (LR6) and Anodonta woodiana was detected only at sites Paks (LR6) and Ráckevei-(Soroksári)-Danube. Inside this faunal group, three smaller groups can be identified: one at LR6 sampling site with extreme high water temperature; another one at sites of the River Ipoly and the Ráckevei-(Sorok-

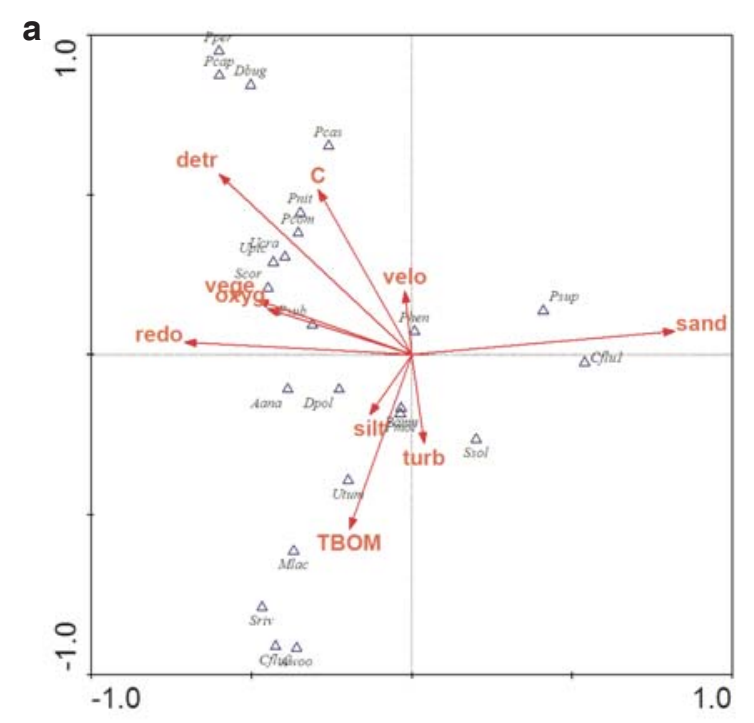

sári)-Danube characterized with similar water discharge and a last one at sites of the Danube with bottom texture of silt and sand.

Group 3 (LR5, LR2 and LR4) corresponded to sites of the main arm of the Danube with bottom texture of pebble, stone and high current velocity. The density and species richness were higher than in group 1, but lower than in group 2 (mean density, Shannon diversity and Pielou's evenness of 16.5 ind. $\mathrm{m}^{-2}, 0.651$ and 0.443 respectively), and a total of 8 species were found. The group was dominated by $C$. flumine and $S$. rivicola.

Canonical correspondence analyses (CCA) were performed to investigate the relationship between the bivalve fauna and the environmental variables (Figure 4). The CCA explained $36.0 \%$ of the variability of species data and $71.5 \%$ of the variability of the species-environment relationship. The eigenvalue for the first axis was 0.516 and for the second axis 0.439 (Table 3). Eigenvalues of CCA axes were significant when tested with Monte Carlo permutations ( 999 permutations, $\mathrm{p}<0.05$ ). Ten environmental variables out of 22 were found to have a significant influence on the composition of bivalve assemblages (Table 4). The strongest explanatory factors were the substrate types, current velocity and the sedimentological characteristics (bed sediment fractions). The first axis reflects the distribution of species and sampling sites along the substrate types and dissolved oxygen, while

b

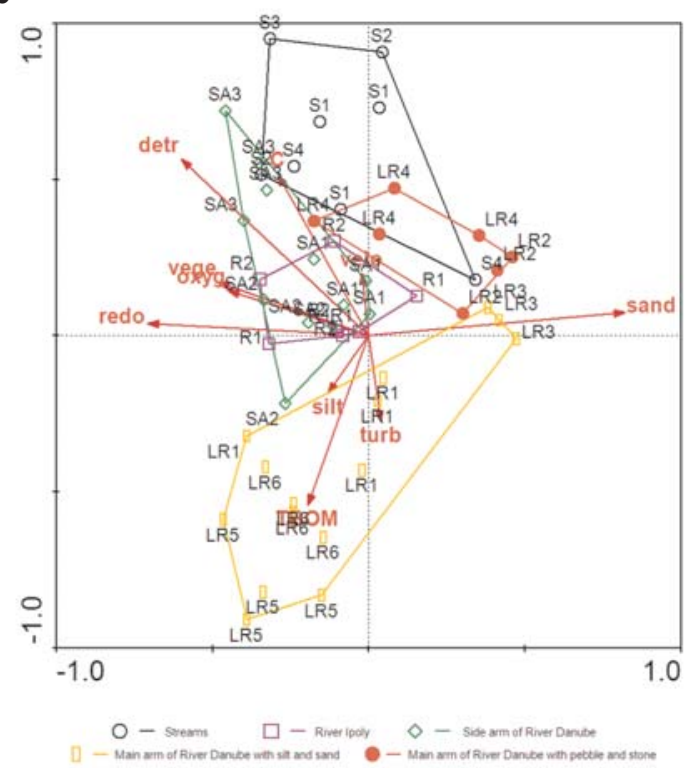

Figure 4. Canonical correspondence analysis (CCA) of bivalve species, environmental variables and sampling sites. a) Biplot of bivalve species and environmental variables. For codes of species: Aana-Anodonta anatina, Awoo-A. woodiana, Cflu1-Corbicula fluminea, Cflu2-C. fluminalis, Dpol-Dreissena polymorpha, Dbug-D. rostriformis bugensis, Mlac-Musculium lacustre, Pamn-Pisidium amnicum, Pcas-P. casertanum, Pcap-P. casertanum var. ponderosum, Phen-P. henslowanum, Pmoi-P.moitessierianum, Pnit-P.nitidum, Pper-P.personatum, Psub-P. subtruncatum, Psup-P. supinum, Pcom-Pseudanodonta complanata, Scor-Sphaerium corneum, Sriv-S. rivicola, Ssol-S. solidum, Ucra-Unio crassus, Upic-U. pictorum, Utum-U. tumidus. For codes of environmental variables: detr-detritus, vege-vegetation, velo-velocity, turb-turbidity, redo-redox potential, oxyg-oxygen content of water, C-coarse fraction of sediment, TBOM-total benthic organic matter. b) Biplot of sampling sites and environmental variables. The codes denote the different sampling sites at 4 different dates. For codes of environmental variables: see Figure $4 \mathrm{a}$. 
the second axis indicates the sedimenthological characteristics and organic matter content of sediment.

There is a special grouping of sites presenting different water types along the investigated longitudinal profile: streams, River Ipoly, side arms of the Danube and the main arm of the Danube with different substrate types. The spatial grouping of sites in the main arm of the Danube can be explained by their substrate types.

Figure 4a presents the location of bivalve species along the same gradient. $P$. personatum and $P$. casertanum are at the positive end of axis 2 . These species appeared especially in streams and preferred the substrate type of detritus (the coarse fraction of sediment), higher current velocity and higher oxygen content. P. nitidum, P. subtruncatum, S. corneum, Pseudanodonta complanata, Unio crassus and U. pictorum located at the middle of axis 2 on the left side of the figure were found principally in River Ipoly and in the side arms, where these species could find a suitable habitat with vegetation and higher oxygen content. $S$. rivicola, $C$. fluminalis, A. woodiana, M. lacustre, U. tumidus, A. anatina, D. polymorha, P. amnicum, P. moitessierianum and S. solidum situated in the lower part of axis 2 were mainly present in the main arm of the Danube and preferred the substrate type of silt and the high organic matter content of sediment. C. fluminea and $P$. supinum located at the middle of axis 2 on the right side of the figure were mainly present in the main arm of the Danube and these species favoured sandy substrates.

\section{Discussion}

This study could serve as a reference situation for malacological surveys in the water system of the River Danube. In total, 22 bivalve species were identified, which represent $79 \%$ of the Hungarian bivalve fauna. Two species (Pseudanodonta complanata and U. crassus) are protected, three (P. amnicum, S. rivicola and S. solidum) are rare, and five (D. polymorpha, D. rostriformis bugensis, C. fluminea, C. fluminalis (morph-2 under revision, Bódis et al. 2011) and $A$. woodiana) are invasive in Hungary.

The most widespread species was $P$. casertanum, which is an eurioecious species (Richnovszky and Pintér 1979). It can live in all types of water bodies (from small ponds and streams to large lakes and rivers). The most abundant bivalve in the whole water system was $P$. subtruncatum. The second most abundant species in the River Danube was $C$. fluminea. This invasive species appeared first in 1999 in the lower part of the Hungarian Danube section (Csányi 1998-1999). Nowadays, due to rapid expansion, $C$. fluminea is one of the most abundant bivalve species in the Hungarian Danube section, its density can reach 736 ind. $\mathrm{m}^{-2}$ in the Danube Bend above Budapest (Bódis 2007b) but it did not invade yet the small rivers and streams running into the Danube. This clam appeared next to the confluence of the River Ipoly and Danube, however, we did not find it in River Ipoly farther from the inflow. This phenomenon can be explained with the environmental demands of this clam, as it prefers the medium and large watercourses (Sousa et al. 2008b). Further, in run- ning waters the expansion of this species is more intensive in downstream than in upstream direction. The dispersal in upstream becomes into foreground only in the case of colonizing empty places and reoccupying disturbed habitats (Bilton et al. 2001).

The higher density presented by $P$. subtruncatum, $P$. supinum, $P$. henslowanum and $C$. fluminea suggests that these species may have a key role in the investigated ecosystem. The small-sized, but abundant sphaeriids affect the nutrient dynamics in freshwater systems, through excretion and biodeposition of faeces and pseudofaeces, and serve as important food resources for higher trophic levels (Vaughn and Hakenkamp 2001). On the other hand, the introduced C. fluminea is recognized as one of the most important aquatic invasive species and it could affect all components of the freshwater ecosystem including native species and environmental processes (Phelps 1994, Cataldo and Boltovskoy 1999, Sousa et al. 2008b).

The freshwater bivalves, especially the family Unionidae, are often considered the most endangered group of animals in the world (Bogan 1993, Lydeard et al. 2004). The rare occurence and low density of Hungarian species belonging to this family (mainly the endangered Unio crassus and Pseudanodonta complanata) enhance the claim for making increased efforts for their conservation and our study could be used in future management actions as a reference about the actual situation.

The concept of river continuum predicts increase in number of species and diversity downstream from springs to the middle course as a result of environmental specialization of animals living in rivers. The spatial pattern of bivalve species shows the same tendency. The lowest species richness was detected in streams, while the highest number of species and diversity appeared in the River Ipoly and in the side arms of the Danube. The sites of streams are characterized by changing water discharge ( $\mathrm{S} 4$ was dried out in August), lower water temperature and $\mathrm{pH}$, and coarser sediments compared to other sites. The sites of the side arms of the Danube and the sites of River Ipoly were abundant in vegetation and their current velocity was low. In general, molluscs have a potamic nature (Mouthon 1981) and they are most diversified in the lower reaches of river systems in contrast with insects (Plecoptera, Trichoptera, Emphemeroptera), which prefer the upper and middle reaches of rivers (Vernaux 1973). However, a decrease in species richness was detected on the lowland regions of the Danube. Although we have no data on the bivalve distribution in the Danube before the severe anthropogenic impact, this decrease could indicate an increasing human pressure. Endangered mussel species were present in the River Ipoly (U. crassus and Pseudanodonta complanata) and in the side arms of the Danube (Pseudanodonta complanata), probably because the side arms and the sites of River Ipoly remain with abundant vegetation and low velocity conditions. It is important to protect these habitats for conservation of molluscan diversity in Hungary. 
Three different bivalve groups were distinguished in this study. The least abundant and diverse group included only two species ( $P$. casertanum and $P$. personatum). Zieritz and Waringer (2008) also found only two bivalve species $(P$. casertanum and P. personatum) along the Weidlingbach, a first to fourth order calcareous sandstone stream in Austria. The most abundant and diverse group was found in the River Ipoly, in the side arms of the Danube and in the main arm of the Danube with sand and silt substrate. The group was dominated by $P$. subtruncatum, $P$. henslowanum and $P$. supinum. Paks sampling site (LR6), which was situated at the outlet of the cooling water channel of the Paks Nuclear Power Plant, has a distinct species composition. Due to the heated water, some species (C. fluminea, C. fluminalis and $A$. woodiana) can live there attaining great densities. The third group with moderate density and species richness was dominated by $C$. fluminea, $S$. rivicola and $P$. supinum. These species can be adapted to harder substrate types such as pebbles and stones.

The spatial grouping of sites and species can be explained on a local and a landscape scale. Our results showed that landscape scale effects (e.g., water types and longitudinal gradient) determine the spatial pattern of sites and bivalve assemblages along the investigated second order streamlarge river continuum. However, the local effects (e.g., substrate types, current velocity and sedimentological characteristics (bed sediment fractions)) were the strongest explanatory factors. Numerous studies dealing with the spatial distribution of macroinvertebrates call attention to the relative importance of physical factors in structuring their communities at a smaller, local scale. In most cases, the hydraulic and substratum conditions were identified as key environmental factors affecting the benthic community structure (Rempel et al. 2000, Eedy and Giberson 2007). Our results are in accordance with previous studies (Pardo and Armitage 1997, Beisel et al. 1998, Brown 2003, Heino et al. 2004, Jurkiewicz-Karnkowska and Zbikowski 2004, Brooks et al. 2005, Beaty et al. 2006, Sousa 2007, 2008a, Miserendino 2009) which show that substrate type, current velocity and sediment characteristics play the most important role in the distribution of benthic species, including molluscs.

Large rivers consist of patches of habitats linked by diverse processes, and are characterized mostly with discontinuity. Based on the species composition of macroinvertebrate assemblages, three sections could be detected in the main arm of the Danube: the section above Gönyü, a section between Gönyủ to Budapest and another one from Budapest to Mohács (Nosek and Oertel 2008). According to our results, the bivalve composition in the main arm of the Danube does not separate into different sections along the upstreamdownstream gradient. Indeed, the spatial grouping of sites can be explained by local effects, mainly by the substrate types and current velocity, which could contribute to the discontinuity concept of large rivers. Freshwater bivalve assemblages appear to be most influenced by current velocity and substratum characteristics that are, in turn, determined by stream size and surface geology (Strayer 1983). Although these factors broadly influence bivalve distribution and di- versity, preference for particular physical variables is not known quantitatively for many species (Holland-Bartels 1990) in riverine ecosystems. This is especially true for the small-sized family Sphaeriidae, for which the habitat requirements are poorly known. On the other hand, at least a dozen studies over the last 30 years have shown strong positive correlations between the abundance and diversity of freshwater molluscs and calcium concentration or related water quality variables (hardness, $\mathrm{pH}$, alkalinity and conductivity) (Dillon 2000). We measured the $\mathrm{pH}$ and conductivity of sampling sites, but these environmental factors did not change considerably over sites and dates and probably their influence on the distribution of bivalves is small.

According to our results, $P$. personatum and $P$. casertanum find suitable habitat in streams mainly characterized with detritus, coarser sediment, higher current velocity and higher oxygen content of water column. Zieritz and Waringer (2008) also observed that these species were most abundant in detritus-rich sediment. $P$. nitidum, $P$. subtruncatum, $S$. corneum, Pseudanodonta complanata, Unio crassus and $U$. pictorum were found principally in River Ipoly and in the side arms, which can be described with dense vegetation and higher oxygen content of water. Our results are in accordance with the observation of Meier-Brook (1969), who found that $P$. nitidum had its greatest abundance in dense vegetation and preferred the water sufficiently rich in oxygen. S. rivicola, $C$. fluminalis, A. woodiana, M. lacustre, U. tumidus, A. anatina, D. polymorha, $P$. amnicum, $P$. moitessierianum and $S$. solidum were mainly present in the main arm of the Danube and preferred the substrate type of sand or silt with high organic matter content of sediment, which is in accordance with previous studies (Boycott 1936, Tóth and Bába 1981, Belanger et al. 1985, Sousa et al. 2008 c,d).

In conclusion, this study provides baseline information that can be used in future ecological and conservational studies in this important area of the Danube hydrological basin. However, further works are required to understand the natural spatial and temporal dynamics of malacological assemblages in the complete Hungarian Danube section to estimate the influence of increasing anthropogenic disturbances. Finally, the presence (almost $20 \%$ of the entire bivalve fauna) of invasive bivalve species in the Hungarian Danube stretch indicates the urgent need to study their effects on native biota and ecosystem functioning.

Acknowledgements: The project was financially supported by the Hungarian Scientific Research Fund under the contract No. OTKA T/046180. Special thanks to the DanubeIpoly National Park for the help in field work.

\section{References}

Beaty, S.R., Fortino, K. and Hershey, A.E. 2006. Distribution and growth of benthic macroinvertebrates among different patch types of the littoral zones of two arctic lakes. Freshwater Biol. 51: 2347-2361.

Beisel, J.-N., Usseglio-Polatera, P., Thomas, S. and Moreteau, J.C. 1998. Stream community structure in relation to spatial vari- 
ation: the influence of habitat characteristics. Hydrobiologia 389: 73-88.

Belanger, S., Farris, J., Cherry, D. and Cairns, J. 1985. Sediment preference of the freshwater Asiatic clam, Corbicula fluminea. Nautilus 99: 66-72.

Bij de Vaate, A., Jazdzewski, K., Ketelaars, H.A.M., Gollasch, S. and Van der Velde, G. 2002. Geographical patterns in range extension of Poto-Caspian macroinvertebrate species in Europe. Can. J. Fish. Aquat. Sci. 59: 1159-1174.

Bilton, D.T., Freeland, J.R. and Okamura, B. 2001. Dispersal in freshwater invertebrates. Annu. Rev. Ecol. Syst. 32: 159-181.

Bogan, A.E. 1993. Freshwater bivalve extinctions (Mollusca: Unionoidae): a search for causes. Am. Zool. 33: 599-609.

Boycott, A. 1936. The habitats of freshwater mollusca in Britain. $J$. Anim. Ecol. 5: 116-186.

Bódis, E. 2007a. Spatio-temporal pattern of the small-sized mussel fauna in the Danube above Budapest. Acta Biol. Debr. Oecol. Hung. 16: 21-32.

Bódis, E. 2007b. The biomass dynamics of Corbicula fluminea invasive mussel. Acta Biol. Debr. Oecol. Hung. 16: 9-20.

Bódis, E., Nosek, J. and Oertel, N. 2008a. Spatio-temporal pattern of mussels (Corbiculidae, Dreissenidae, Sphaeriidae) in the watersystem of the Hungarian Danube. Arch. Hydrobiol. Suppl. Large Rivers 18(1-2): 293-308.

Bódis, E. 2008b. Contribution to the macroinvertebrate fauna of Hungarian Danube IV. Mussels (Bivalvia: Corbiculidae, Dreissenidae, Sphaeriidae, Unionidae). Fol. Hist.-Nat. Mus. Matraensis 32: 57-68.

Bódis, E., Nosek, J., Oertel, N., Tóth, B. and Fehér, Z. 2011. A Comparative study of two Corbicula morphs (Bivalvia, Corbiculidae) inhabiting River Danube. Internat. Rev. Hydrobiol. 96(3): 257-273.

Brown, B.L. 2003. Spatial heterogeneity reduces temporal variability in stream insect communities. Ecol. Lett. 6: 316-325.

Brooks, A.J., Haeusler, T., Reinfelds, I. and Williams, S. 2005. Hydraulic microhabitats and distribution of macroinvertebrate assemblages in riffles. Freshwater Biol. 50: 331-344.

Cataldo, D. and Boltovskoy, D. 1999. Population dynamics of Corbicula fluminea (Bivalvia) in the Paraná River Delta (Argentina). Hydrobiologia 380: 153-169.

Clarke, K.R. and Green, R.H. 1988. Statistical design and analysis for a biological effects study. Mar. Ecol. Prog. Ser. 46: 213-226.

Clarke, K.R. and Warwick, R.M. 2001. Change in Marine Communities: An Approach to Statistical Analysis and Interpretation, second ed. PRIMER-E Ltd., Plymouth Marine Laboratory, UK.

Csányi, B. 1998-1999. Spreading invaders along the Danubian highway: first record of Corbicula fluminea and C. fluminalis in Hungary. Fol. Hist. Nat.-Mus. Matr. 23: 343-345.

Dillon, R.T. 2000. The Ecology of Freshwater Molluscs. Cambridge University Press, Cambridge.

Eedy, R.I. and Giberson, D.J. 2007. Macroinvertebrate distribution in a reach of a north temperate eastern Canadian river: Relative importance of detritus, substrate and flow. Arch. Hydrobiol. 169(2): 101-114.

Falkner, G., Bank, R. A. and Proschwitz, T. von 2001. Check-list of the non-marine molluscan species-group taxa of states of northern, atlantic and central Europe (CLECOM I). Heldia 4: 1-76.

Fehér, Z. and Gubányi, A. 2001. The Distribution of Hungarian Molluscs. The Catalogue of the Mollusca Collection of the Hungarian Natural History Museum, Budapest.
Fehér, Z., Majoros, G. and Varga, A. 2004. A scoring method for the assessment of rarity and conservation value of the Hungarian freshwater molluscs. Heldia 6: 127-140.

Felföldy, L. 1987. The Biological Water Quality, $4^{\text {th }}$ Revised edn. Vízügyi Hidrobiológia 16, VGI Budapest (in Hungarian).

Gelwick, F.P. 1990. Longitudinal and temporal comparisons of riffle and pool fish assemblages in a North-eastern Oklahoma Ozark Stream. Copeia 1990: 1072-1082.

Grossman, G.D., Ratajzak, R.E., Crawford, M. and Freeman, M.C. 1998. Assemblage organisation in stream fishes: effects of environmental variation and interspecific interactions. Ecol. Monogr. 68: 395-420.

Haas, G., Brunke, M. and Streit, B. 2002. Fast turnover in dominance of exotic species in the Rhine river determines biodiversity and ecosystem function: an affair between amphipods and mussels. In: Leppakoski E. et al. (eds.), Invasive Aquatic Species of Europe, Kluwer, Netherlands. pp. 426-432.

Hammer, O., Harper, D.A.T. and Ryan, P.D. 2001. Past: paleontological statistics software package for education and data analysis. Palaeontologia Electronica, vol. 4, issue 1, art. 4.

Heino, J., Louhi, P. and Muotka, T. 2004. Identifying the scales of variability in stream macroinvertebrate abundance, functional composition and assemblage structure. Freshwater Biol. 49: 1230-1239.

Holland-Bartels, L.E. 1990. Physical factors and their influence on the mussel fauna of a main channel border habitat of the upper Mississippi River. J. N. Am. Benthol. Soc. 9: 327-335.

Huryn, A.D. and Wallace, J.B. 1987. Local geomorphology as determinant of macrofaunal production in a mountain stream. Ecology 68: 1932-1942.

Jurkiewicz-Karnkowska, E. and Zbikowski, J. 2004. Long-term changes and spatial variability of mollusc communities in selected habitats within the dam reservoir (Wloclawek Reservoir, Vistula River, Central Poland). Pol. J. Ecol. 52(4): 491-503.

Lydeard, C., Cowie, R.H., Ponder, W.F. et al. 2004. The global decline of nonmarine molluscs. Bioscience 54: 321-330.

Martinez, B., Velasco, J., Suárez M. L., Vidal-Abarca M. R. 1998. Benthic organic matter dynamics in an intermittent stream in South-East Spain. Arch. Hydrobiol. 141(3): 303-320.

Meier-Brook C. 1969. Substrate relations in some Pisidium species (Eulamellibranchiata: Sphaeriidae). Malacologia 9: 121-125.

Minshall, G.W., Cummins, K.W., Petersen, R.C., Cushing, C.E., Bruns, D.A., Sedell, J.R. and Vannote, R.L. 1985. Developments in stream ecosystem theory. Can. J. Fish. Aquat. Sci. 42: 1045-1055.

Miserendino, M.L. 2009. Effects of flow regulation, basin characteristics and land-use on macroinvertebrate communities in a large arid Patagonian river. Biodivers. Conserv. 18: 1921-1943.

Mouthon J. 1981. Typologie des Mollusquses des eaux courantes. Organisation biotypologique et groupements socioecologiques. Ann. Limnol. 17(2): 143-162.

Mouthon, J. 1999. Longitudinal organisation of the mollusc species in a theoretical French river. Hydrobiologia 390: 117-128.

Nosek, J. and Oertel, N. 2008. Similarity patterns of macroinvertebrate communities in the Hungarian Danube and adjecent wetlands (Szigetköz and Gemenc). Arch. Hydrobiol. Suppl. Large Rivers 18(1-2): 243-256.

Pardo, I. and Armitage, P.D. 1997. Species assemblages as descriptors of mesohabitats. Hydrobiologia 344: 111-128. 
Phelps, H. L. 1994. The Asiatic clam (Corbicula fluminea) invasion and system-level ecological change in the Potomac River Estuary near Washington, D. C. Estuaries 17(3): 614-621.

Richnovszky, A. 1967. Data to the Mollusk Fauna of the Flood Area of the Danube. Opusc. Zool. 7(1): 195-205.

Richnovszky, A. and Pintér, L. 1979. Freshwater Snails and Bivalves (Mollusca). In: Felföldy L. (series ed.), Vízügyi Hidrológia 6, VIZDOK Budapest.

Rempel, L.L., Richardson, J.S. and Healey, M.C. 2000. Macroinvertebrate community structure along gradients of hydraulic and sedimentary conditions in a large gravel-bed river. Freshwater Biol. 45: 7-73.

Sousa, R., Antunes, C. and Guilhermino, L. 2007. Species composition and monthly variation of the Molluscan fauna in the freshwater subtidal area of the River Minho estuary. Estuar. Coast. Shelf Sci. 75: 90-100.

Sousa, R., Dias, S., Freitas, V. and Antunes C. 2008a. Subtidal macrozoobenthic assemblages along the River Minho estuarine gradient (north-west Iberian Peninsula). Aquat. Conserv. 18: $1063-1077$.

Sousa, R., Antunes, C. and Guilhermino, L. 2008b. Ecology of the invasive Asian clam Corbicula fluminea (Müller, 1774) in aquatic ecosystems: an overview. Ann. Limnol. 44: 85-94.

Sousa, R., Nogueira, A.J.A., Antunes, C. and Guilhermino, L. 2008c. Growth and production of Pisidium amnicum (Müller, 1774) in the freshwater tidal area of the River Minho estuary. Estuar. Coast. Shelf Sci. 79: 467-474.

Sousa, R., Morais, P., Antunes, C. and Guilhermino, L. 2008d. Factors affecting Pisidium amnicum (Müller, 1774; Bivalvia: Sphaeriidae) distribution in the River Minho estuary: consequences for its conservation. Estuar. Coast 31: 1198-1207.

Sousa, R., Gutiérrez, J.L. and Aldridge D.C. 2009. Non-indigenous invasive bivalves as ecosystem engineers. Biol. Invasions 11: 2367-2385.

Strayer, D.L. 1983. The effects of surface geology and stream size on freshwater mussel (Bivalvia, Unionidae) distribution in southeastern Michigan, U.S.A. Freshwater Biol. 13: 253-264.

Strayer, D.L., Downing, J.A., Haag, W.R., King, T.L., Layzer, J.B., Newton, T.J. and Nichols, S.J. 2004. Changing perspectives on pearly mussels, North America's most imperiled animals. BioScience 54: 429-439.

Szekeres, J., Molnár, M., Csányi, B. and Szalóky, Z. 2009. Macrozoobenthon investigations on two Danube cross-sections (Rajka and Szob) with dredging method. Acta Biol. Debr. Oecol. Hung. 20: 209-218.

Ter Braak, C.J.F. and Smilauer, P. 2002. CANOCO Reference manual and CanoDraw fro Windows User's guide: Software for Ca- nonical Community Ordination (ver. 4.5) Biometris, Wageningen \& Ceské Budejovice.

Tóth, M. and Bába, K. 1981. The mollusca fauna of the Tisza and its tributaries. Tiscia (Szeged) 16: 169-181.

Töry, K. 1952. The River Danube and its Regulation. Akadémiai Kiadó, Budapest.

Vannote, R.L., Minshall, G.W., Cummins, K.W., Sedell, J.R. and Cushing, C.E. 1980. The river continuum concept. Can. J. Fish. Aquat. Sci. 37: 130-137.

Varga, A., Csányi, B., and Majoros, G. 1998-1999. Data on distribution of mussel species in Hungarian rivers based on faunal research of the last decade II. (Mollusca-Bivalvia). Fol. Hist.-Nat. Mus. Matraensis 23: 347-367.

Varga, A. and Csányi, B. 1996. Malacological data from the upper part of the Danube in Hungary (1994). Malacol. Newsletter 15: 77-88.

Vaughn, C.C. and Hakenkamp, C.C. 2001. The functional role of burrowing bivalves in freshwater ecosystems. Freshwater Biol. 46: 1431-1446.

Vaughn, C.C. and Spooner, D.E. 2006. Scale-dependent associations between native freshwater mussels and invasive Corbicula. Hydrobiologia 568: 331-339.

Vernaux, J. 1973. Cours d'eau de Franche-Comté (massif du Jura) recherches écologiques sur le réseau hydrographique du Doubs. Essai de biotypologie. These Doct. Sci. Nat., Univ. Besancon: 1-257.

Zieritz, A. and Waringer, J. 2008. Distribution patterns and habitat characterization of aquatic Mollusca in the Weidlingbach near Vienna, Austria. Arch. Hydrobiol., Suppl. Large Rivers 18: 271292.

Received November 22, 2010 Revised June 9, 2011

\section{Appendices}

Appendix 1. Environmental characteristics of the sampling sites.

Appendix 2. Annual average density of freshwater bivalve species.

The file may be downloaded from the web site of the publisher at www.akademiai.com. 